Polémica 



\section{Réplica a Antonio Carreira}

En el número anterior (33-2) de esta revista se publicó una nota del filólogo español Antonio Carreira ("Crítica de la edición crítica") que constituye una "Respuesta a Margit Frenk". Responde, en efecto, a un artículo ("Un poema en movimiento") en el que he cuestionado la metodología utilizada actualmente en las ediciones más serias de poemas líricos españoles de los siglos XVI y XVII. A modo de ejemplo, analizo la edición que hizo A. Carreira de un famoso romancillo de Góngora, el primero de su impresionante edición crítica de los romances del poeta y atribuidos a él. Para que se sepa de qué estamos hablando, necesito exponer brevemente los antecedentes de ese debate.

El Siglo de Oro español fue una época de enorme actividad poética, una actividad que rara vez desembocaba en libros impresos y sí, frecuentemente, en manuscritos. El proceso de transmisión se ha venido describiendo así: garabateado por el poeta en un papel, el texto del poema era copiado por aficionados en papeles sueltos que, a su vez, volvían a copiarse y que eventualmente podían ir a dar, junto con otros, a un cartapacio y a un manuscrito de "Poesías varias de diferentes autores". Y este manuscrito, por su parte, servía para alimentar nuevas copias. En el curso de la transmisión el poema se desprendía casi siempre del nombre de su autor y circulaba anónimamente; además, iba generando variantes, ya involuntarias, ya deliberadas. Como casi nunca se conserva el texto original, lo que el editor moderno tiene frente a sí son los manuscritos y alguno que otro impreso, que manifiestan a las claras el laberíntico proceso de la transmisión.

El editor que ejerce la "crítica textual" aspira a establecer un texto que se acerque lo más posible a lo que considera que fue el perdido poema original. Se abre camino entre las muchas versiones y va desechando todas las variantes claramente erróneas y también las que él juzga desacertadas y ajenas al estilo del poeta y por tanto advenedizas, espurias. Por lo general, publica entonces una sola versión y da cuenta, sintéticamente, de las demás y de sus variantes. 
Frente a esta manera de proceder y a la visión de las cosas que implica se alza otra concepción distinta, para la cual la transmisión no se limitaba en esa época a copias de copias, sino que incluía una dimensión que no suele interesar a la crítica textual: la de la memoria y la voz. Como he tratado de mostrar en otros sitios, la memoria y la voz tuvieron un papel protagónico en la difusión de las obras escritas, y esto, desde la Antigüedad, durante la Edad Media y todavía en los siglos XVI y XVII. Sobre la poesía española de estos dos siglos, decía yo en el mencionado artículo:

En el caso de los poemas breves, ya narrativos ya líricos, la enorme importancia que tuvieron la memoria y la voz — la voz que recitaba y la voz que cantaba - no debería soslayarse nunca, porque implica [un] hecho fundamental [...]: que los poemas, por cultos que fueran [...], no constituían textos fijos, inmóviles. La memorización y las repeticiones orales de los poemas hacían que estos fueran cambiando, en un proceso dinámico que los mantenía en continuo movimiento, en un estado de fluidez parecido al de la poesía popular (“Un poema”, 106-107).

Algunas de las innumerables repeticiones orales o "vocales" de los poemas iban a dar a las antologías poéticas manuscritas e impresas. Estas reflejan, entonces, no solo la labor de los copistas, sino también y a menudo la circulación memorística de los poemas y su oralización. Recordemos además su generalizado anonimato, fenómeno importante, porque es "como si la autoría no tuviera mayor importancia, como si toda poesía fuera considerada un bien común, y la gente se sintiera con derecho a meterle mano" (107). ${ }^{1}$ Olvidado el nombre del poeta y perdido el texto que él había compuesto, el poema se embarcaba en una nueva existencia, sin por ello perder generalmente su esencia original, su identidad primigenia.

Si la crítica textual establece para cada poema un texto único y rechaza o relega las variantes, la otra visión de las cosas considera que el poema, en esas circunstancias, no tiene un solo texto, fijo e inmutable, y ve con interés las variantes, pues - dejando de lado los errores evidentes - revelan la vida que el ya anónimo poema cobraba en boca de la gente que lo recitaba y lo cantaba. Era un proceso análogo, aunque no igual, al de la circulación de las canciones

${ }^{1}$ Rodríguez-Moñino (Poesía, 26) habla sobre "el diverso concepto que, en siglos pasados, autorizaba la refundición de obra ajena", y Alberto Blecua (Manual, 211) ha dicho que "la refundición es fenómeno igualmente frecuente en una sociedad habituada a las glosas, a los contrafacta, a la traducción-imitación, y que todavía siente la obra literaria como un bien común que puede modificarse". Véase Frenk, Entre la voz,143n. 
populares. A propósito de la tradición oral, decía José María Díez Borque en 1985 (El libro, 47): "Lo que supone la crítica textual de fijeza, de búsqueda de unidad en la diversidad, de pureza, de conversión del texto en monumento inalterable [es] todo lo contrario [...] de la movilidad fluyente, de la variación como norma".

Mi artículo se centró en el análisis de la edición del divulgadísimo romancillo de Góngora "La más bella niña / de nuestro lugar" (Romances, I, 184-189), que Carreira encontró en nada menos que 38 manuscritos y ocho impresos contemporáneos. De entre todos ellos, eligió la versión del códice de 1628 que contiene los poemas de Góngora reunidos por Antonio Chacón tras ocho años de colaboración con el propio poeta y después de haber consultado abundantes manuscritos. Una fuente autorizada, pues, pero una fuente compilada más de treinta años después de la fecha de 1580 que el mismo códice adjudica a "La más bella niña". Todas las demás versiones quedan comprimidas en el impresionante "aparato de variantes", donde se registran, pasaje tras pasaje, las discrepancias que esas 45 versiones presentan con respecto a la elegida como "canónica" (la palabra es de Carreira). He aquí el hermoso romancillo, tal como figura en la citada edición:

\author{
La más bella niña \\ de nuestro lugar, \\ hoy vïuda y sola \\ y ayer por casar, \\ viendo que sus ojos \\ a la guerra van, \\ a su madre dice, \\ que escucha su mal: \\ Dejadme llorar \\ orillas del mar.
}

5

10

Pues me distes, madre,

en tan tierna edad

tan corto el placer,

tan largo el pesar,

15

y me cautivastes

de quien hoy se va

y lleva las llaves

de mi libertad,

dejadme llorar

orillas del mar. 
En llorar conviertan

mis ojos, de hoy más,

el sabroso oficio

del dulce mirar,

25

pues que no se pueden

mejor ocupar,

yéndose a la guerra

quien era mi paz.

Dejadme llorar

30

orillas del mar.

No me pongáis freno

ni queráis culpar,

que lo uno es justo,

lo otro, por demás;

35

si me queréis bien,

no me hagáis mal;

harto peor fuera

morir y callar.

Dejadme llorar

orillas del mar.

Dulce madre mía,

¿quién no llorará,

aunque tenga el pecho

como un pedernal,

45

y no dará voces,

(5)

viendo marchitar

los más verdes años

de mi mocedad?

Dejadme llorar

50

orillas del mar.

Váyanse las noches,

pues ido se han

los ojos que hacían

los míos velar;

55

váyanse y no vean

(6)

tanta soledad,

después que en mi lecho

sobra la mitad. 
Para dar una idea del aparato de variantes, la del verso 8 se registra así en la edición de Carreira: "escucha] escuche $A j, C I S, C o ́, f 1, f 2, f 13, J M H, M 2$, $M 614, \operatorname{Mod}, \mathrm{rg}, S, W \ldots$... Eso quiere decir que en todas las fuentes mencionadas el verso 8 aparece como "que escuche su mal", y no "que escucha". Las letras están ordenadas alfabéticamente, o sea, sin un criterio que permita jerarquizarlas. Para saber qué significa cada una, hay que acudir a la sección de "Fuentes" (49-115); ahí nos enteramos de la ubicación y de ciertas características de cada fuente. $^{2}$

Dada la manera como está hecho el aparato de variantes, se dificulta enormemente la reconstrucción de otras versiones. Sin embargo, valió la pena intentarlo, al menos parcialmente. Al hacerlo, encontré cosas interesantes, de las que fui dando cuenta en mi estudio.

Una de ellas fue la importancia de las primeras versiones conocidas, todas ellas impresas. La primera, de 1589 (f1), está trunca, pero la de 1591 (f2), no, y sucede que fue reimpresa dos veces $(1592,1600=f 13, r g)$ y por ello dejó su huella en muchos otros testimonios. Para Carreira es el "texto primitivo" del romancillo, pero, como dije, "es poco probable que lo fuera, dados los muchos años transcurridos [desde 1580, la fecha de composición], en que el poemita debe de haber circulado abundantemente: las diferencias entre 1589 y 1591 son botón de muestra de esa difusión" ("Un poema", 114). Es importante notar que, juntas, las versiones de 1589 y 1591 ya incluyen, en otro orden, cinco de las seis secuencias o "estrofas" de la que para Carreira es la versión "madura" y definitiva del poema. La otra secuencia (versos 31-38) no parece ser de Góngora, pues presenta a la "dulce madre", no como una confidente de la adolorida muchacha, sino como una mujer represora, que le "pone freno", la "culpa" y le hace daño, todo ello, dicho en unos versos torpes y torpemente hilvanados.

Pese a los rasgos — no son muchos - que la diferencian de la versión de Chacón, la de 1591 ya es en esencia la de $1628,{ }^{3}$ de modo que, a mi juicio, debería haberse impreso entera en la edición de Carreira, en vez de aparecer segmentada en el apretado aparato de variantes.

Carreira ve con malos ojos ciertas "variantes" — ¿variantes a priori, previas al texto "variado"? — de las primeras versiones, impresas, que a mí me parecie-

2 Para las fuentes de otros romances, a veces se nos ofrecen indicaciones como: copia de tal otro manuscrito, copia con descuidos, buen manuscrito, etcétera.

${ }^{3}$ Discrepo ahora de mi opinión anterior, pues allá consideraba la versión de 1591 un poema distinto del posterior. 
ron interesantes y válidas. No acepta, en el verso 3, "hoy es viuda y sola", forma en que el verso figura en bastantes testimonios más, lo que prueba que así lo decían muchos (y sus razones tendrían: si otra versión que entonces circulaba decía "hoy vïuda", se habrá querido evitar el hiato en vi/uda y la aglomeración de cuatro vocales, oi-iu). Tampoco le gusta "A su madre dice / que escuche su mal" (v. 6), igualmente frecuente, como hemos visto. Tan convencido está nuestro filólogo de que el único texto aceptable del romancillo gongorino es el que él canonizó, que no acepta ninguna desviación, por mínima que sea, y para cada caso presenta una detenida justificación del texto chaconiano. Claro, cualquier cosa puede justificarse de alguna manera.

Pero veamos todas las "variantes". Su gran abundancia ya da que pensar. ¿Tantos errores o desaciertos de copistas? ¿No más bien indicios de una gran difusión memorística y oral? Decía José F. Montesinos de los romances de Lope de Vega que "las versiones conservadas ofrecen típicas variantes de transmisión oral" (Poesías líricas, $\mathrm{IX}$ ). Lo mismo ocurre con nuestro romancillo gongorino. Entre sus "variantes" encontramos sustituciones de una palabra por otra equivalente: "mejor emplear" / "mejor ocupar", "los más tiernos años" / "los más verdes años"; sustitución de una palabra por otra disímil: "quien era mi paz" / "quien lleva mi paz". Diferente forma verbal: "quién no llorará" / "quién no ha de llorar"; inversión de elementos: "Pues me distes, madre" / "Madre, pues me distes"; nuevas formulaciones de la misma idea: "viendo que sus ojos / a la guerra van" / "porque sus amores / a la guerra van" (vv. 5-6); "yéndose a la guerra" / "viendo ir a la guerra" / "y se va a la guerra" (vv. 27-28). ${ }^{4}$ Son fenómenos que no suelen producirse cuando un texto se copia de otro texto, pese al hecho de que, como se nos dice, el copista memorizaba las palabras y luego se las dictaba a sí mismo: el proceso era demasiado rápido para que ocurran, verosímilmente, cambios como los apuntados. ${ }^{5}$

Otro indicio de memorización son los cambios de lugar de las estrofas. En un romance como el nuestro, mucho más lírico que narrativo, las secuencias tienen tanta independencia, que la memoria suele hacerlas cambiar de sitio dentro de la composición. Guiándonos por la organización de la versión canónica, que no es más que una de tantas, vemos que la versión impresa en 1591 las ordena de esta manera (véanse los números a la derecha del texto aquí

${ }^{4}$ Véase Frank, Entre la voz, 149.

${ }^{5}$ Claro que la memorización y la oralización también producen disparates, que suelen coincidir con los que ocurren al copiar, como en palabras que se escucharon mal: "conciertan mis ojos", por "conviertan", v. 15; "harto pedir fuera", por "harto peor fuera", v. 37; "quien hará mi paz" o "quien era mi par", por "quien era mi paz", v. 28; y el peor de todos: "porque en mi lecho / sobra la amistad", vv. 57- 58. 
reproducido): 1-5-6-3; en el cancionero manuscrito de Jhoan López el orden es 1-5-2-3; en otro, de la Brancacchiana: 1-6-2-3, y el aparato de variantes muestra otras ordenaciones. Esta fluctuación típicamente memorística no suele darse cuando un texto escrito se copia de otro texto escrito. En vista de todo lo anterior, pregunto: ¿no son estas prueba suficiente del papel protagónico que la memoria desempeñaba en la transmisión de los textos? Yo diría que sí lo son.

Hay una variación que me parece especialmente interesante: la del estribillo. En Chacón y en algunos otros testimonios consta de dos hexasílabos: "Dexadme llorar / orillas del mar", con una regularidad métrica que no tiene en la mayoría de las fuentes, desde las del siglo xvi; ahí el estribillo reza "Dexadme llorar / orillas de la mar", con esa ligera irregularidad de muchas canciones populares. El estribillo es, sin duda, creación de Góngora, quien, a mi ver, prefirió originalmente el "de la mar", palabras que al cantar solían repetirse: "de la mar, de la mar...".

El asunto no carece de importancia, pero Carreira no se manifiesta al respecto. En cambio, en su "respuesta" se detiene en la curiosa "variante" que encontré impresa dos veces en 1591, “...orillas del amar". Según él, se trata de una errata debida "a que la regleta de separación se colocó [¿dos veces?] en lugar indebido" (214); y como si hiciera falta, documenta este tipo de erratas con varios casos de la misma fuente. Luego se mofa de una observación que hice entre paréntesis: "(Pienso que ya en el 'orillas de la mar' resuena subterráneamente esa otra idea [orillas del amar]...)", y explico por qué: "La jovencita recién casada y ya abandonada estaba apenas viviendo el sabroso oficio del dulce mirar y eran solo los ojos de él los que la desvelaban: se encontraba realmente a las orillas del amar") ("Un poema", 114). Carreira pretende divertirse a mi costa:

Una hermosa novela cuyo único fallo es admitir para un estribillo del siglo XVI una metáfora vanguardista. Ese amar con orillas es aún más moderno que el cantarcillo que puso Rulfo en Pedro Páramo: 'Mi novia me dio un pañuelo / con orillas de llorar", pues al fin un pañuelo puede tener huellas de llanto en sus bordes, mientras que el amar, difícilmente (215).

Por supuesto, es imposible que el amar tuviera huellas de llanto en sus bordes... Pero, como diría Cervantes, "está el daño" en que esa imagen poética, un pañuelo con orillas de llorar, es mucho más que la prosaica lectura que de ella hace Carreira, el cual no supo lo que hacía cuando trajo a colación, felizmente, esa coplita del siglo xix. En ella el pañuelo no es un simple pedazo de tela, sino un objeto simbólico, frecuente en las coplas populares modernas y siempre 
asociado con el amor, de modo que sus orillas de llanto nos están hablando de un sufrimiento amoroso. Si entendemos esto, de pronto se nos ponen lado a lado el "Dexadme llorar / orillas del amar" y el "pañuelo [=amor] con orillas de llorar". ${ }^{6}$

Por otra parte, en poetas áureos, como, especialmente, Góngora, suele haber metáforas aún más osadas. Unos versos de Garcilaso (Canción IV, vv. 90-91) dicen: "muéstrame l'esperanza / de lejos su vestido y su meneo", pasaje que se refiere al vestido y el "meneo" de la amada, pero que el pastor Antonio, en el romance que canta ante don Quijote (I, XI), convierte en: "Tal vez la esperanza muestra / la orilla de su vestido". Ya que Antonio se dirige a su amada Olalla, ese vestido con orilla no puede ser sino de la esperanza, metáfora tan audaz como las "orillas del amar" de la muy buena versión del romancillo de Góngora publicada en 1591 .

El análisis de todas las variantes me llevó a la conclusión de que la mayor parte de ellas son

buenas alternativas que fueron surgiendo con la memorización y oralización del texto por recitadores, cantantes y aun copistas que, además, se sentirían a veces en libertad de modificar levemente los versos. Son cambios a menudo válidos, y más de uno podría proceder de un buen poeta, incluso del mismo Góngora ("Un poema”,116).

Consta, en efecto, que Góngora, como otros contemporáneos, solía modificar sus poemas cuando los volvía a copiar.

Como puede imaginarse, todo esto de la validez de las variantes le resultó inadmisible a Carreira. Yo había considerada digna de imprimirse entera una versión del manuscrito italiano conservado en Florencia, el magliabechiano VII, 614, códice que Carreira califica ahora de "deleznable". El romancillo contiene ahí varios rasgos interesantes, algunos de ellos compartidos con otros testimonios: "La más linda niña" (v. 1), "Y pues no se pueden" (v. 25), "viendo ir a la guerra" (v. 27). Una variante en especial, que figura también en la versión de un manuscrito conservado en Nápoles, me llamó mucho la atención: en los dos versos maravillosos "después que en mi lecho / sobra la mitad" (vv. 57-58), el manuscrito florentino trae: “... falta la mitad”. Al respecto, escribí ("Un poema", 116): "Se diría, un error, pero no lo es: la mitad le sobra al lecho y le falta a la muchacha". Dicho menos sintéticamente: en el lecho sobra la mitad y a la niña le falta $s u$ mitad, en línea — añado ahora — con la seguidilla

${ }^{6}$ Agradezco a Coral Bracho su valiosa colaboración en este y otros aspectos del presente trabajo. 
que el propio Góngora puso, en 1620, en boca de una mujer cuyo marido está ausente: "La mitad del alma / me lleva el mar: / bolved, galeritas, / por la otra mitad". $7^{7}$

A mi propuesta el señor Carreira replica sarcástico: “ ¿Le falta la misma (sic) mitad que le sobra? No sabemos. La novela sigue su curso, y es lástima que no conozcamos el final" (216). Esto da una idea de la temperatura a la que ha subido esa "respuesta" que comenzó con un "mi admirada Margit Frenk". Más sano hubiera sido decir, sin burlas ofensivas, que no se está de acuerdo con las ideas de esa señora y dar buenos argumentos.

Pero es que Carreira está encerrado en su estrecha concepción de las cosas. $\mathrm{Su}$ "respuesta" rechaza, por principio de cuentas, mi aseveración de que los romances eran memorizados, recitados y cantados: "nos faltan pruebas de que en la transmisión de la poesía culta interviniese la memoria de manera decisiva, y la prueba compete a quien afirma" ("Crítica", 217). Quien afirma (o sea, yo) acaba de citar muchas variantes típicamente memorísticas, pero además, ha venido aduciendo pruebas en trabajos publicados desde 1982 y recogidos en el libro Entre la voz y el silencio, que a Carreira, si acaso lo conoce, no debe interesarle. Ahí hablo largamente, y con pruebas al canto, de la importancia de la memoria (iy de la voz!) en la cultura medieval, renacentista y barroca ${ }^{8}$ y de la abundantísima oralización de los textos escritos, en muy diferentes géneros. Dos estudios incluidos en el libro, uno de 1987 y el otro de 1992, se dedican específicamente a los manuscritos poéticos y a la memorización y oralización de los poemas breves de poetas cultos del Siglo de Oro. Por lo demás, son ya muchos los que defienden esas ideas que Carreira descalifica como "neorrománticas". Cito a algunos. Don Antonio Rodríguez-Moñino, conocedor como nadie de la poesía del Siglo de Oro y de sus modos de transmisión, pudo decir que "la obra corta muchas veces no pasa de copia a copia, sino del recuerdo al papel, de la memoria a la pluma" (Construcción, 26); Alberto Blecua, nada menos que en su Manual de crítica textual (24), hubo de reconocer que "una copia puede haberse basado en el mero recuerdo y sin tener a la vista un modelo"; y con referencia al romancero María Cruz García de Enterría ha escrito que "la escasa fijación de los romances viejos en manuscritos" sería prueba del "papel

${ }^{7}$ Obras poéticas, t. 2, núm. 345.

${ }^{8}$ Se equivoca Carreira cuando dice que Frenk "aplica a la poesía áurea conceptos más bien apropiados a la medieval" (219). Lo mismo, cuando asevera que creo "válidos para la poesía culta criterios que rigen en la popular" (219). No hay tal: la variación en poesía popular es bien distinta, pues se alimenta de elementos preexistentes en la tradición oral, cosa que no puede ocurrir en un poema "culto". Si he señalado semejanzas, es porque un poema culto que circula memorizado y oralizado también va engendrando variantes. 
que la memoria jugó en la transmisión del romancero, mucho más importante y crucial que para cualquier otro tipo de obra poética" ("Romancero", 90). Y tiene razón mi amiga: los romances se prestan mucho más que otros poemas cortos a la memorización y, añado, a la consiguiente variación fecunda. Los sonetos, para citar un caso opuesto, también se memorizaban, pero los olvidos y las sustituciones podían no ajustarse a la estricta geometría rímica del poema y conducir, entonces, a francos dislates.

En cierto momento dice Carreira que "la oralidad del romancero, incluida la del viejo, estuvo siempre muy reforzada y retroalimentada por la escritura, cosa que las teorías neorrománticas han tendido a silenciar" (216). Sorprende que aquí reconozca la oralidad del romancero, y lo que dice sobre la retroalimentación de la escritura es totalmente cierto, como lo he expuesto con creces en los dos trabajos ahora mencionados. En "El manuscrito poético, cómplice de la memoria" digo, a la letra: "A los manuscritos se acudiría para leer y releer los poemas, las más veces, en voz alta, por cierto; pero también para grabarlos y afianzarlos en el recuerdo: venían siendo, pues [...] un apoyo para la oralización" (Entre la voz, 150). ${ }^{9}$

También: "la escritura, la copia de poemas, iba del brazo de la memoria y la oralización" (149). Mis "reflexiones acerca de la función de la memoria en la literatura antigua" ("Crítica", 211) vienen de décadas atrás, y de ninguna manera "se apoyan sobre todo en el Éloge de la variante de Bernard Cerquiglini (Paris, Seuil, 1989)", puesto que, como digo expresamente, a este inventivo autor (a quien solo conozco desde hace poco) "la memoria y la voz [...] no le interesan mayormente" ("Un poema", 106). ${ }^{10}$ ¿No se supone que uno debe leer bien los trabajos contra los que uno polemiza?

Cerquiligni sostiene, sí, la movilidad de los textos medievales y su carencia de un texto fijo, pero - y en esto coincide curiosamente con Carreira- a base únicamente de los documentos escritos. Puesto que, como gloso en mi artículo, la transmisión de un texto "dependía de una compleja combinación de ejecutantes, poetas y copistas —un atelier d'écriture —, ningún texto era inalterable; todos estaban sujetos a una constante reescritura" ("Un poema", 106).

En su "respuesta", Carreira se detiene largamente en la cuestión de los cancioneros musicales de la época. Yo había notado que él no le dio importancia al hecho de que "varios de los testimonios utilizados son cancioneros polifó-

9 Véase igualmente "La poesía oralizada y sus mil variantes", Entre la voz, 121135.

10 En una nota cito este pasaje: "On ne prendra pas ici la défense de l'oral, du corps, de la voix" ("Un poema”, 106, n. 6). Es un probable rechazo de las ideas de Paul Zumthor. 
nicos" ("Un poema", 110-111). Él contrargumenta ahora que el hecho sí se "indica, siempre, al fin de cada prefacio" a los 94 romances ("Crítica", 211), o sea, como dato pertinente para la edición de cada romance, pero no como un fenómeno al que haya que darle el peso que tuvo y que, a mi ver, debió mencionarse en la Introducción. Es bien sabido que los cancioneros musicales ofrecen versiones truncas de los poemas, cosa que Carreira vuelve a documentar minuciosamente, para concluir que "ni con la mejor voluntad se las puede tener en cuenta para establecer un texto crítico" (212). Tiene toda la razón del mundo. Pero la cosa no iba por ahí: pese a su escasez, los cancioneros musicales para mí constituyen simplemente una prueba valiosa de que los romances (viejos y nuevos) se cantaban. El hecho de que aparezcan truncos en los cancioneros podría explicarse incluso porque los cantores se sabrían el texto completo y no necesitaban tenerlo ante los ojos.

Aún más valiosos para nuestro propósito son los manuscritos poéticos que incluyen cifras para guitarra, pues no solo vienen a confirmar que los romances nuevos se cantaban, sino que tenían melodías bien conocidas, de modo que solo hacía falta enseñarles a los cantores qué acordes tocar para acompañar su canto con la guitarra. De hecho, para nosotros hoy esas cifras son frustrantes: desearíamos conocer la melodía; pero como todos se la sabían, no hacía falta registrarla.

Dice A. Carreira en su "respuesta":

La escasez de transcripciones musicales ${ }^{11}$ conservadas en 'mentirosos cartapacios', se compadece muy mal con lo de que el romancero nuevo sea un género 'consustancialmente cantado', y menos aún con que semejante canturía, cuando se da, tenga algo que ver con la transmisión real de los textos (213).

La lógica de la primera aseveración se me escapa (no era, ni es, fácil escribir una partitura musical), y en cuanto a la segunda, impresiona el desprecio con que trata, por una parte, la música polifónica de aquel tiempo y, por otra, la difusión de los poemas, que él coloca muy por debajo de su "transmisión real", o sea, de la escrita: los cancioneros musicales, dirá poco después, "no pertenecen a la transmisión textual de Góngora sino a su difusión, cosa muy distinta" (212). Y qué bien que lo haya dicho con tal claridad. La crítica textual a la $\mathrm{Ca}$ rreira se interesa exclusivamente por la "transmisión textual", o sea, la que se manifiesta, negro sobre blanco, en los papeles conservados; presupone que eso

${ }^{11}$ No son transcripciones, sino composiciones polifónicas hechas por músicos profesionales. 
que está escrito ahí fue necesariamente copiado de otro texto escrito, siempre de los ojos al papel. La difusión oral y memorística de la poesía no le interesa; sabe que existió, pero la descarta de antemano. Para él, como para otros neopositivistas, lo que no consta en papeles no existe. Si don Quijote cita de memoria muchos romances, eso se lo inventó Cervantes; si un filólogo actual insiste en que los papeles conservados no necesariamente son copias deficientes de otras copias, eso es especulación pura, cuando no "novela".

Así, la "crítica de la edición crítica" resulta no tener mucho sentido crítico. Y a este propósito, uno esperaría encontrar en la "respuesta" comentarios sobre varias cosas de "Un poema" que no se mencionan siquiera. ¿Por qué, por ejemplo, no se dice nada sobre el anonimato de las versiones de este romance, como de los demás? ¿Acaso no es un hecho significativo? ¿Por qué no se pronuncia una palabra sobre esa cuarta secuencia (versos 31-38) de la versión canónica, a la que yo califiqué de "pobre" (y fue poco decir)? ¿Solo porque forma parte de la versión del poema, única aceptada? ¿Por qué tampoco se pronuncia Carreira sobre las dos formas del estribillo? Y así podríamos seguir preguntando, me temo que inútilmente. ¿Acaso tendría sentido sugerirle a Carreira que considere la posibilidad de que las versiones de Chacón no sean necesariamente las mejores y de que haya otras igualmente dignas de publicarse?

Pero seamos justos. Hacia el final de la "respuesta" encontramos con sorpresa una especie de palinodia: dice Carreira que, a pesar de sus puntos débiles,

mi artículo lo ha hecho reflexionar. Él, que ha subtitulado "Edición crítica" a la edición de los romances de Góngora, cuestiona ahora "la conveniencia de hacer ediciones críticas en la poesía del Siglo de Oro". Añade que "por algo ese mismo rótulo no aparece en las debidas a filólogos competentes, como José Manuel Blecua o Biruté Ciplijauskaité, en las cuales hay aparato crítico, pero no texto que así pueda calificarse" (219). Las ediciones de poesía del Siglo de Oro que tienen en cuenta todos los testimonios conocidos "no son, pues, críticas en sentido estricto [...]; en realidad podrían designarse variorum editiones..." (220). ¿Variorum, cuando casi no permiten conocer, incluso, otras buenas versiones? En todo caso, seguimos, claro, atados a la escritura. Lo que no podrá reconocer Carreira es lo que he llamado "la otra visión". Y es que, evidentemente, se trata de dos posiciones antagónicas e irreconciliables. ¿Qué le vamos a hacer?

MARgit FrenK 


\section{REFERENCIAS}

Blecua, Alberto, Manual de crítica textual, Madrid, Castalia, 1983.

CARreira, Antonio, "Crítica de la edición crítica. Respuesta a Margit Frenk", Acta Poetica, 33-2, julio-diciembre 2012, 211-221.

Díez Borque, José María, El libro: de la tradición oral a la cultura impresa, Barcelona, Montesinos, 1985.

Frenk, Margit, "La poesía oralizada y sus mil variantes" [1987], en Entre la voz, 121-135.

Frenk, Margit, "El manuscrito poético, cómplice de la memoria" [1992], en Entre la voz, 136-151.

Frenk, Margit, Entre la voz y el silencio. La lectura en tiempos de Cervantes, México, Fondo de Cultura Económica, 2005.

Frenk, Margit, "Un poema en movimiento: La más bella niña, de Luis de Góngora", en Itziar López Guil y Jenaro Talens (eds.), El espacio del poema. Teoría y práctica del discurso poético, Madrid, Biblioteca Nueva, 2011, 105-117.

García de EnTERRÍA, María Cruz, "Romancero: ¿cantado-recitado-leído?", Edad de Oro, 7, 1988, 89-104.

Góngora, Luis de, Obras poéticas, ed. R. Foulché-Delbosc, 3 vols., Nueva York, Hispanic Society of America, 1921. Ed. facsimilar, Nueva York, Hispanic Society of America, 1970.

GóngorA, Luis de, Romances, ed. Antonio Carreira, 4 vols. Barcelona, Quaderns Crema, 1998.

Montesinos, José F., Prólogo a Lope de Vega, Poesías líricas, 2 vols., Madrid, Espasa-Calpe, 1963.

Rodríguez-MoÑIno, Antonio, Construcción crítica y realidad histórica en la poesía española de los siglos XVI y XVII, Madrid, Castalia, 1965.

Rodríguez-MoÑIno, Antonio, Poesía y cancioneros, Madrid, Real Academia Española, 1968. 